Canadian Studies in Population, Vol. 37.1-2, Spring/Summer, pp. 77-105

\title{
The Influence of Characteristics of Men's Job on the Timing of the First Birth in Canada
}

\author{
Germain Bingoly-Liworo \\ Département de démographie \\ Université de Montréal \\ E-mail: gbingoly@yahoo.fr
}

\begin{abstract}
The objective of the study was to illustrate the impact of characteristics of the job of at least six months held by men born from 1930 to 1965 on the timing of the first birth. The hypothesis is that characteristics of the job occupied at the beginning career lead to a differential transition to parenthood, characterized by a greater likelihood of having a first child for men whose job shows stability, compared with those whose first job is unstable and precarious. The data used are derived from the Statistics Canada 2001 General Social Survey, to which applied methods are used in event history analysis. The results validate the hypothesis, in indicating that full-time wage earners and self-employed workers have a greater likelihood of having a first child than part-time wage-earners. Results also show that the effect of characteristics of the job is limited in the first five years spent on the job. In addition, the job seems to accelerate the transition to parenthood for men married before being hired. All of the results suggest the need for family support to help young couples become established and for governments to adopt measures to encourage young people's work integration.
\end{abstract}

Key Words: Men, characteristics of the job, birth of the first child

CSP 2010, 37.1-2: 77-105 


\section{Résumé}

L'étude visait à illustrer l'impact des caractéristiques de l'emploi d'au moins six mois des hommes des générations 1930-1965 sur l'arrivée du premier enfant. L'hypothèse est que les caractéristiques de l'emploi occupé en début de carrière induisent une transition différentielle au statut de parent: caractérisée par une plus grande propension à avoir un premier enfant parmi les hommes dont l'emploi témoigne une stabilité, comparativement à ceux dont l'emploi est moins rassurant en raison de ces caractéristiques. Les données utilisées proviennent de l'ESG 2001 réalisée par Statistique Canada, auxquelles nous avons appliqué les méthodes d'analyse biographique. Les résultats valident notre hypothèse, en indiquant que les salariés travaillant à temps plein et les travailleurs autonomes ont une forte propension à avoir un premier enfant que les salariés travaillant à temps partiel. Nos résultats montrent également que l'effet des caractéristiques de l'emploi est limité dans les cinq premières années passées sur le marché du travail. De même, l'emploi en début de carrière semble être un accélérateur du passage au statut de parent chez les hommes mariés avant l'embauche. L'ensemble de nos résultats suggère le soutien familial à l'établissement des jeunes couples et que les gouvernements adoptent des mesures pour favoriser l'insertion professionnelle des jeunes en début de carrière.

Mots clés : Hommes, caractéristiques de l'emploi, arrivée du premier enfant

\section{Introduction}

For most men, the establishment of a family has always been influenced by their becoming established in an appropriate economic status. This prerequisite is of course not a formally prescribed norm, but has always been tacitly accepted in almost all societies. Its importance is linked to the fact that the statuses of husband and father are accompanied by economic responsibilities for dependents. But over the past few decades, the labour market has been affected by significant change, influenced by technological innovations, new forms of work and production organization, and new trade regulations stemming from globalization. These historic changes are apparently leading to greater instability and precariousness, at least for newly hired individuals. At the same time, family and reproductive behaviours have also been marked by a wide range of profound changes. These include, for example, the postponement of first births, 
The Influence of Characteristics of Men's Job on the Timing of the First Birth in Canada

which has been happening more and more often in many industrialized countries, including Canada. To explain this, the literature links first birth postponement to a complex series of factors, including young people's economic precariousness at the time of their starting family life (Blossfeld and Mills 2003; De Wit and Rajulton 1992; Bingoly-Liworo and Lapierre-Adamcyk 2006). But in most studies, the relation between young people's economic precariousness and fertility has been analyzed by comparing the reproductive behaviours of persons in the labour force with those of unemployed people, without making any distinctions by job status or the nature of the job. But for young people in the midst of their transition to adulthood, their first labour market experiences are determining factors both in their personal emancipation and in the synchronization of other life cycle events.

This study examines men's transition to parenthood in relation to characteristics of the job ${ }^{1}$. The study attempts to answer the following question: to what extent do characteristics associated with the job ooccupied at the career beginning full-time wage work, part-time wage work, and self-employment) enable us to better define differences in the transition to parenthood for the first time? The data used are the event histories of Canadians born from 1930 to 1965, collected during the General Social Survey, Cycle 15, on the family, conducted by Statistics Canada in 2001.

The first part looks at theoretical and empirical considerations related to sociological and economic hypotheses concerning the delaying of family events. Its aim is to place our reflection in a theoretical framework. The second part presents the data and our analysis methodology. The third part briefly describes the evolution of both the survival probability in job and the timing of men's first birth over the generations, taking into account the time elapsed since the men's hiring. Finally, the fourth part presents our results regarding the impact of characteristics associated with the job occupied at the beginning career on men's likelihood of becoming a parent, controlling for certain relevant personal characteristics.

\section{Theoretical and Empirical Considerations}

This study falls within the perspective of the transition to adulthood. On a quantitative level, analysis of this process has concentrated on three markers: union formation, entry into a first job, and access to first housing (Tichit and Lelièvre 2006: 198). Our study concerns on one portion of this process, as some people in the sample had apparently already experienced certain key events in the transition to adulthood. We take as our point of departure of jobs lasting at least six months; and the event under study is the birth of the first child. The interest of examining the transition to parenthood from the time of men's labour market entry is linked to the growing role of work integration in the acquisition 
of autonomy. For most men, realizing their plans to establish a family is still seen from the perspective of personal emancipation, which is itself in part dependent on their being established in stable work. As with the research that has examined the timing of entry into parenthood starting from the date of union formation, our study takes a similar approach but applies it to the interdependent processes of labour market entry and the birth of a first child. However, recent studies have pointed to an increasingly blurred transition-to-adulthood model where the synchronization of thresholds and evolution of the meaning of events seem to be especially affected (Tichit and Lelièvre 2006: 200), compared with the "typical" trajectory that apparently prevailed in the 1950s. Nevertheless, our exploratory analyses suggest that for most young Canadians, the first job and first birth still follow this chronological order, although we see a diversification of the paths leading to personal independence, their extension in time and the instability of certain key events. Thus, like other events ${ }^{2}$ in the transition-toadulthood process (Galland 1996; Ravanera et al. 2002), the first birth is occurring increasingly later on in Canada. This phenomenon, which has intensified over the past few decades, involves men's fertility timetables as much as it does women's. The explanations offered come for the most part from demographic, sociological and economic studies or theories. Some of the most unanimously accepted explanations advanced in demography are related to the use of modern contraceptive methods and easy access to induced abortion (in the United States, Westoff and Ryder 1977; in France, Léridon et al. 1987; Roussel 1987; and in Québec, Lapierre-Adamcyk and Marcil-Gratton 1987; Henripin 1989)

Explanations of a sociological nature look at various types of factors. The most recent are linked to the functioning of industrialized societies. Among these are the interpretations offered by van de Kaa (1987) in the context of the theory of the second demographic transition. This paradigm associates contemporary fertility behaviours with certain changes that have occurred in western societies, particularly those affecting the ways couples live together. Among other things, the theory of the second demographic transition emphasizes women's growing control over reproduction and their increasing power in both the family sphere and other areas (more egalitarian sexual relations; the political, legal and economic arenas), due to a continual appreciation of their human capital, supported by the de-institutionalization of individual behaviours. For Oppenheimer (1994) and Palomba (2001), the changes in demographic behaviours observed in recent decades do not simply affect women. Young people of both sexes are in fact studying for longer periods of time in order to achieve their life goals. They are consequently postponing living as a couple and the carrying out of their plans to have children. 
The Influence of Characteristics of Men's Job on the Timing of the First Birth in Canada

Economic explanations of first birth postponement that directly concern men are mainly derived from the economic theory of tension between material aspirations and resources as advanced by Easterlin (1976) and Easterlin et al. $(1990,1991)$. There are also certain emerging interpretations that consider the role of global economic conditions and changing modes of labour market participation, and the repercussions of this on men's establishment in stable work. According to the theory of relative economic status, the postponement of young adults living on their own and the development of new lifestyles (shared housing or youth cohabitation) would result from a desire to maintain the level of consumption experienced in adolescence, as the economic situation of young men newly entering the labour market deteriorates. In such conditions, women's contribution to household income is largely being solicited, which is leading to a delay in family formation. Overall, this economic theory of fertility neglects the sociocultural component of the behaviours in question.

Some emerging explanations of family and reproductive behaviours are based on the finding of an extension of the period of youth. To explain this phenomenon, McDonald (2001) and Blossfeld and Mills (2003) emphasize the climate of uncertainty that characterizes individual life courses. According to McDonald, the uncertainties affecting various dimensions of the lives of many of our contemporaries are prompting them to invest in their security (for example, in education) rather than face the insecurity connected with having children (low income during the maternity period, difficult labour market reentry, higher consumption expenses, economic responsibilities for dependents). Following a comparative study in 14 countries on the impact of globalization on the evolution of young people's life cycles, Blossfeld and Mills (2003) conclude that uncertainty has a real impact on young people's transition to union formation and parenthood. Young people's reactions to this situation take the form of various strategies such as the postponement of certain life plans, an extension of the duration of studies or the decision not to undertake more demanding projects. Some studies have already validated these hypotheses (e.g., Mongeau et al. 2001). These researchers maintain that: Men who have not yet begun to work regularly are half as likely to form a union as those who have worked at a regular job without interruption. Similarly, Duval (1997) points out that within the couple, the stability of the man's income at the time of having a child is more crucial than is that of the woman's.

In Canada, examination of the impact of characteristics associated with men's job on the transition to parenthood is assuming an increasing importance, as demographic studies are highlighting a widespread postponement of first births. At the same time, research on young people's work integration is pointing to precarious and less stable jobs held by newly hired individuals, especially younger persons. In Canada, current modes of work integration are in fact taking more and more time to lead to regular jobs (Gauthier et al. 2002; Bowlby 2000; Vosko et al. 2003). In a recent study entitled "Les bons emplois

CSP 2010, 37.1-2: 77-105 
disparaissent-ils au Canada?", Morissette and Johnson (2005) conclude that, from 1981 to 2004, the median hourly wages of newly-hired workers of both sexes declined in relation to those of other wage-earners, and that the relative importance of temporary jobs is markedly increasing.

In light of the literature review and empirical findings, the hypothesis to be tested is that variance in characteristics associated with the job occupied at the beginning career lead to a differential transition to parenthood, characterized by a greater likelihood of having a first child for men whose job shows some degree of stability, compared with those whose job is unstable and precarious.

\section{Data Source, Variables and Analysis Methodology}

\section{Data Source}

The data used come from Statistics Canada's 2001 General Social Survey (GSS) on the family. This retrospective study involved a stratified representative sample of 24,310 individuals, including 10,664 men aged 15 and older and residing in the ten provinces, excluding the Northwest Territories and Yukon and persons living in institutions. A number of areas are examined, including the respondents' reproductive and work-life histories and socio-demographic characteristics. The GSS thus provides information on the date of arrival of international immigrants (citizens or permanent residents) responding to the survey. The data collected on reproductive life histories give us information on the respondent's number of biological children, children's birth order and respondent's age at the birth of each child. The work histories give us the respondent's age at the beginning and end of each work episode, as well as information about the types of jobs and work regimes. The jobs considered in the questionnaire are those lasting a minimum of six months. The data gathered on the various jobs held allow us to distinguish full-time wage earners from part-time wage-earners, as well as the categories of "self-employed workers" and "family workers." Dating of the beginning and end of each work episode allows us to establish the time spent in each job. The GSS 2001 does not however provide information on the respondents' income, spouses' work histories, or job professions or activity sectors. This lack of information obliges us to characterize the job only by type of job held and work regime.

The analysis sample is comprised of 6,764 men aged 36 to 71 at the date of the survey, who stated they had had regular work lasting at least six months. The job occupied at the beginning career considered is a job obtained at age 15 at the earliest and age 34 at the latest. The upper age limit was set at age 34 inclusively from the perspective of analyzing the transition to adulthood. In these conditions, one surmises that the fertility behaviour of men aged 35 and older at the time of hiring would involve another set of issues, in regard to which 
The Influence of Characteristics of Men's Job on the Timing of the First Birth in Canada

one would probably have different objectives. The setting of the lower age limit at age 15 takes into account men's biological maturity in terms of the likelihood of their engendering a child. It should also be noted that immigrant interviewees who had had their first child before coming to Canada are excluded from the analysis, due to the fact that the transition studied must have occurred in Canada. The survival analysis sample is comprised of 4,997 men born between 1930 and 1965 (see Appendix).

\section{Variables Included in the Analyses}

Dependent variable The dependent variable, or the event that we are attempting to explain, is the likelihood of having a first child after having been hired in the job for men aged 15 to 34 at the beginning of the job. In other words, for each time unit observed, the analysis considers the risk of becoming a parent: the higher this risk is, the most likely the transition to parenthood will occur.

Main Independent Variable In this study, we use characteristics associated with the job occupied at the beginning career as the main independent variable. These involve occupational status and work regime (full-time wage-earners, part-time wage-earners and self-employed workers). We considered all episodes of work in a first job before the birth of the first child; this variable is treated as a time-varying variable. The objective is to show the impact of job precariousness on men's transition to parenthood for the first time after being hired in their job, all other things being equal. In general, we expect to find a differential and variable effect of characteristics of the job on men's instantaneous probability of having a first child according to the duration interval in the job. Full-time wage-earners and self-employed workers would be more likely to have their first child shortly after their hiring, whereas, for the same durations in the first job, part-time wage-earners would show less likelihood. It is understood that part-time work is associated with precariousness and economic insecurity, given the low income and lack of protection usually found in this type of job. Involuntary part-time workers are generally less often unionized and are subject to layoffs (technical unemployment) when business slackens.

Other Individual Characteristics Included in the Analysis The sociodemographic characteristics selected are those often identified in the literature as discriminant in regard to fertility behaviour. Two groups of variables are tested: permanent characteristics and characteristics that vary over time. The so-called permanent characteristics that we selected are: birth cohort, age at the beginning of the job, highest level of education attained at the time of hiring, religious practice at age 15 , place of residence at the time of the survey, number of

CSP 2010, 37.1-2: 77-105 
siblings and parents' national origin. As the job characteristics in the first work episode mentioned earlier, marital status is considered to be a characteristic that varies over time. From the perspective of the transition-to-adulthood process, establishment in a conjugal union is considered socially as a prerequisite to the birth of a first child. On this subject, a number of studies emphasize that a stable work and conjugal situation is closely linked to young people having a first child (Gauthier 1991). Galland (1985) states that for unemployed young men, marriage is conditional on a stable work situation, and postponement of the latter almost inevitably results in postponement of the former. Moreover, men's marital status indirectly allows us to take into account the effect of women's characteristics. Men's marital status shows whether the marriage took place before or after the hiring in the job. Four definitions are used for marital status: unattached, married before the hiring, married after the hiring, and living in a common-law union. One of the concerns linked to the use of these categories lies in attempting to understand the differential influence of the type of union on the risk studied. The expectation is that there will be a high risk of having a first child when the man is married before entering into a job, compared with men living in common-law unions. The effect of this factor is measured in specific job duration intervals, in supposing that the influence of marital status varies differently according to the job duration interval. Women's labour force participation rates were also included in the model; those rates correspond to the period where male respondents are assumed to be in the labour force.(i.e. from 1945 to 2001). These rates are treated as time-varying independent variables.

\section{Analytical Approach and Methods}

We initially estimate the model for the entire sample. We then stratify the sample into three groups of generations and estimate a model for each group. We use the generational approach due to the fact that our sample population had experienced different contexts in terms of both the conditions and modes of labour market entry and changing attitudes toward the family. Two statistical analysis methods are used: Kaplan Meier curves and the piecewise model. The latter method involves estimating distribution parameters only over a short time interval, starting again with the next time interval, and so on. The risk is thus broken down into a series of exponential distributions (Le Goff 2003). The method is based on the hypothesis of non-proportionality (Cox 1972) of the basic risk and thus on variability of the effect of individual characteristics according to time in a specific way.

The population at risk of experiencing the event studied is composed of men who had not had a child before being hired in the job. This delimitation allows us to study the transition to fatherhood for individuals who, in terms of the unfolding of the life cycle, are supposed to be in the midst of the various 
The Influence of Characteristics of Men's Job on the Timing of the First Birth in Canada

stages in the transition to adulthood, independently of the order in which they occur. The key event considered is the entry into the labour market. The Kaplan Meier survival analysis curve examines men's likelihood of becoming a parent starting from the time they begin their regular job lasting at least six months. The median duration and intensity of the first birth derived from the survival curves are the parameters selected to describe the rate of this transition. Similarly, for the three generations, and using the smoothed hazard function estimator, we analyze the rate of evolution of men's risk of having a first child after being hired in their job. In order to produce results representative of the total Canadian population, Statistics Canada bootstrap weights were applied to

the GSS2001 data; this was done to take into account the complex sampling design used for the survey.

\section{Entry into the Job Occupied at the Beginning of Career and Birth of the First Child}

\section{Rate of Exit from the Job for Generations of Men Born from 1930 to 1965}

In this section, we describe the exit from the job for men aged 36 to 71 in 2001, at the time of the survey. The job considered consists of regular work lasting at least six months (except for jobs held when the individual was pursuing his studies). This job must have been obtained at age 15 at the earliest and age 34 at the latest.

Figure 1 below presents the Kaplan Meier survival curves for exit from the job for the three male generations born 1930-1949, 1950-1959 and 1960-1965. These curves were adjusted by age at the beginning of the first job in the first work episode. This adjustment neutralizes the effect of the age at the outset of the first work episode on the probability of remaining employed distribution.

These curves show the evolution of the risk of leaving the job according to the time elapsed since the hiring. They thus show the speed with which men of various generations left their job. We can see differences among the three generations in the rate of exit from the job. LogRank and Wilcoxon tests show these differences to be significant to $1 \%$. The younger generations of men left their job earlier. Some $25 \%$ of men born from 1960 to 1965 left their job 6 years at the latest after being hired, while during the observed period only $5 \%$ of the 1930-1940 generation left their job. This leads us to believe that for more recent generations, jobs are more fragile and precarious. On the other hand, for durations of less than 3 years, the two youngest generations (1950-59 and 1960- 


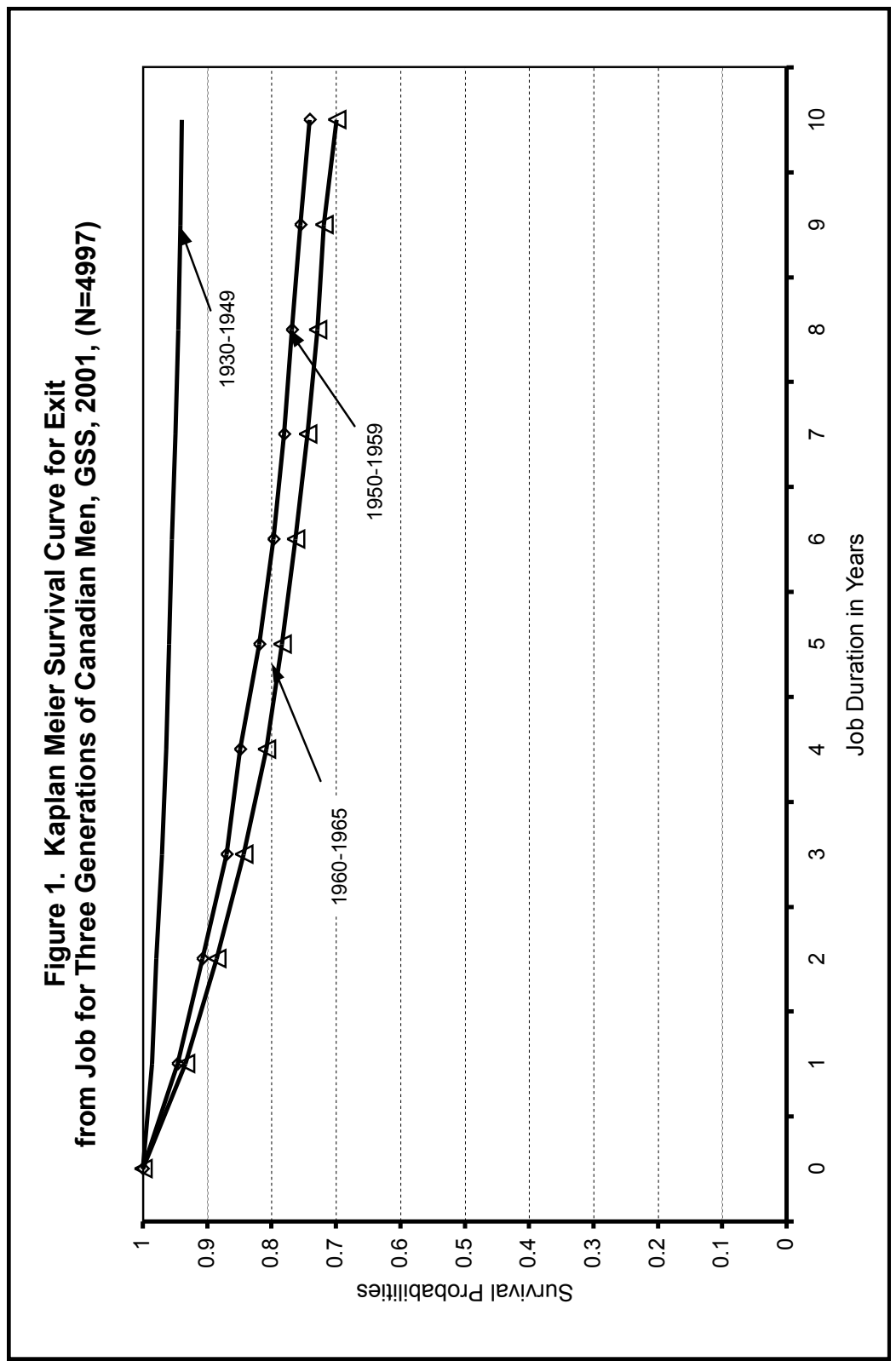

CSP 2010, 37.1-2: 77-105 
The Influence of Characteristics of Men's Job on the Timing of the First Birth in Canada

65) appear to behave similarly. After 3years, the two curves for these generations tend to show an increasing difference. We think that for the recent generations, the job occupied at the beginning career is more unstable and precarious. This implies that for most young people in recent generations, the job may take on a provisional and thus less reassuring nature in terms of carrying out their plans to have children. So the question is whether there is a link between the characteristics of the job and men's transition to parenthood. We will try to bring out this relationship in the following sections. But let us first look at the rate at which the generations born from 1930 to 1965 made their transition to parenthood after being hired in their job.

\section{Transition to Parenthood for Male Generations Born from 1930 to 1965}

Figure 2 shows the speed of transition to parenthood by birth cohort from the time of hiring in the job. Wilcoxon and LogRank statistical tests ${ }^{3}$ are significant, confirming the fact that men's transition to parenthood happened differently for recent generations. During the first few years in the beginning of the job, men in the three generations show a similar behaviour in the transition to parenthood. Up to about four years after their hiring, a little over $78 \%$ of men in each generation have not yet had their first child. The difference between the two older generations and the most recent birth cohort becomes quite clear as of the fifth year, when the survival curve for men born 1960-1965 moves off to the right. This phenomenon illustrates the delay in arrival of the first birth for these generations. The median duration for birth of the first child in the two oldest male generations is about 9 years, compared with just over 11 years for men born between 1960 and 1965. As for the intensity of the first birth, if the tendency shown by individuals in the youngest generation remains the same in the future, there will apparently be a few more men born between 1960 and 1965 who will not have any children at all. We think that this generational effect is, among other things, related to labour market participation conditions, which seem to be less favourable for the younger generations. It also seems that for men born from 1960 to 1965 , entry into the job and birth of a first child are less closely associated.

Moreover, the smoothed hazard function estimator (Figure 3) confirms the results shown by the Kaplan Meier curves (Figure 2) and also sheds more light on the matter. This curve graphically represents rates of transition to parenthood according to the time spent in the job. It shows the conditional probability of having a first child at a given job duration for men who have accumulated that number of years in their job and have not yet had a first child. Unlike the survival curve, the smoothed hazard function estimator shows that the

CSP 2010, 37.1-2: 77-105 


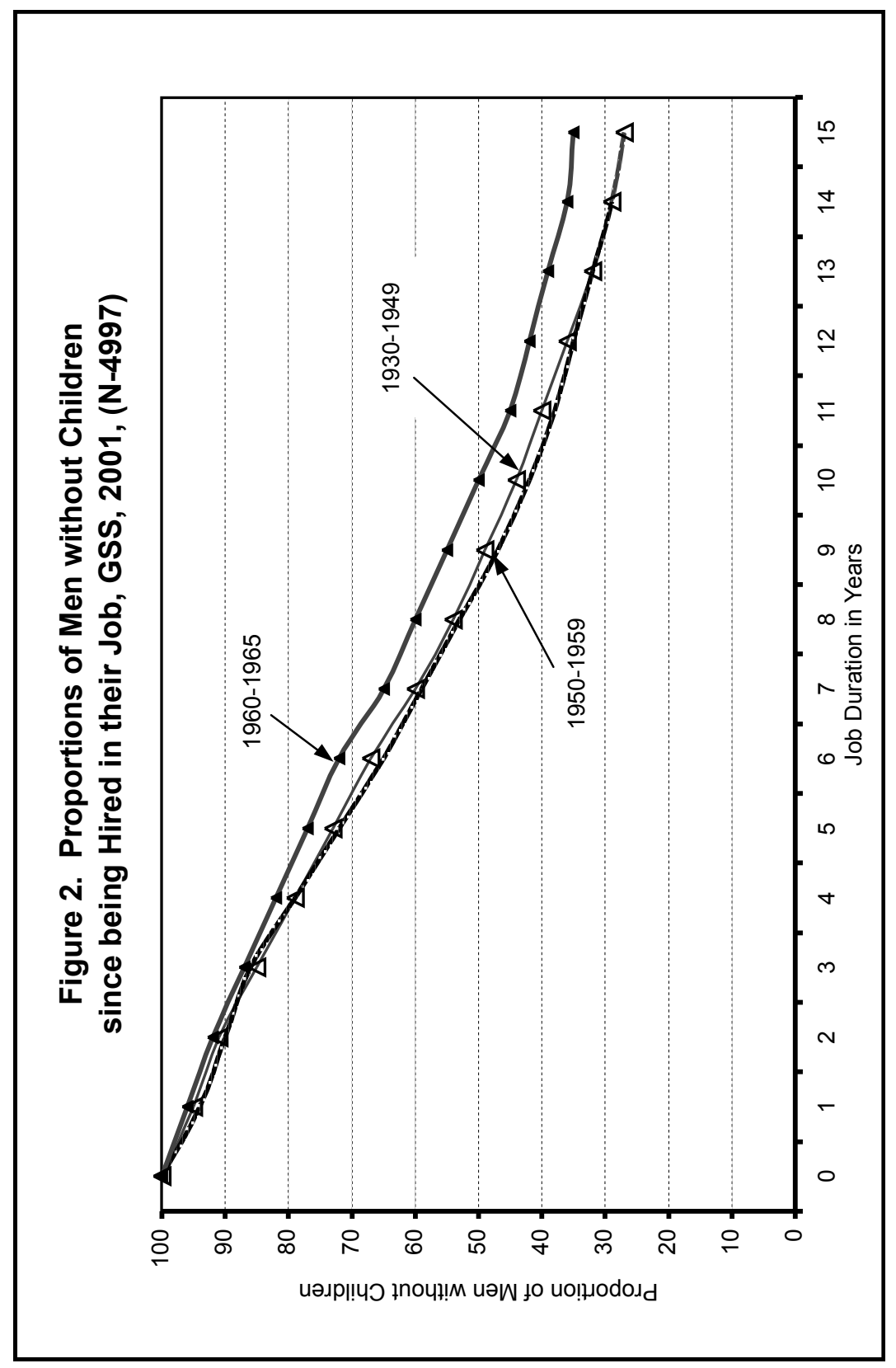

CSP 2010, 37.1-2: 77-105 
The Influence of Characteristics of Men's Job on the Timing of the First Birth in Canada

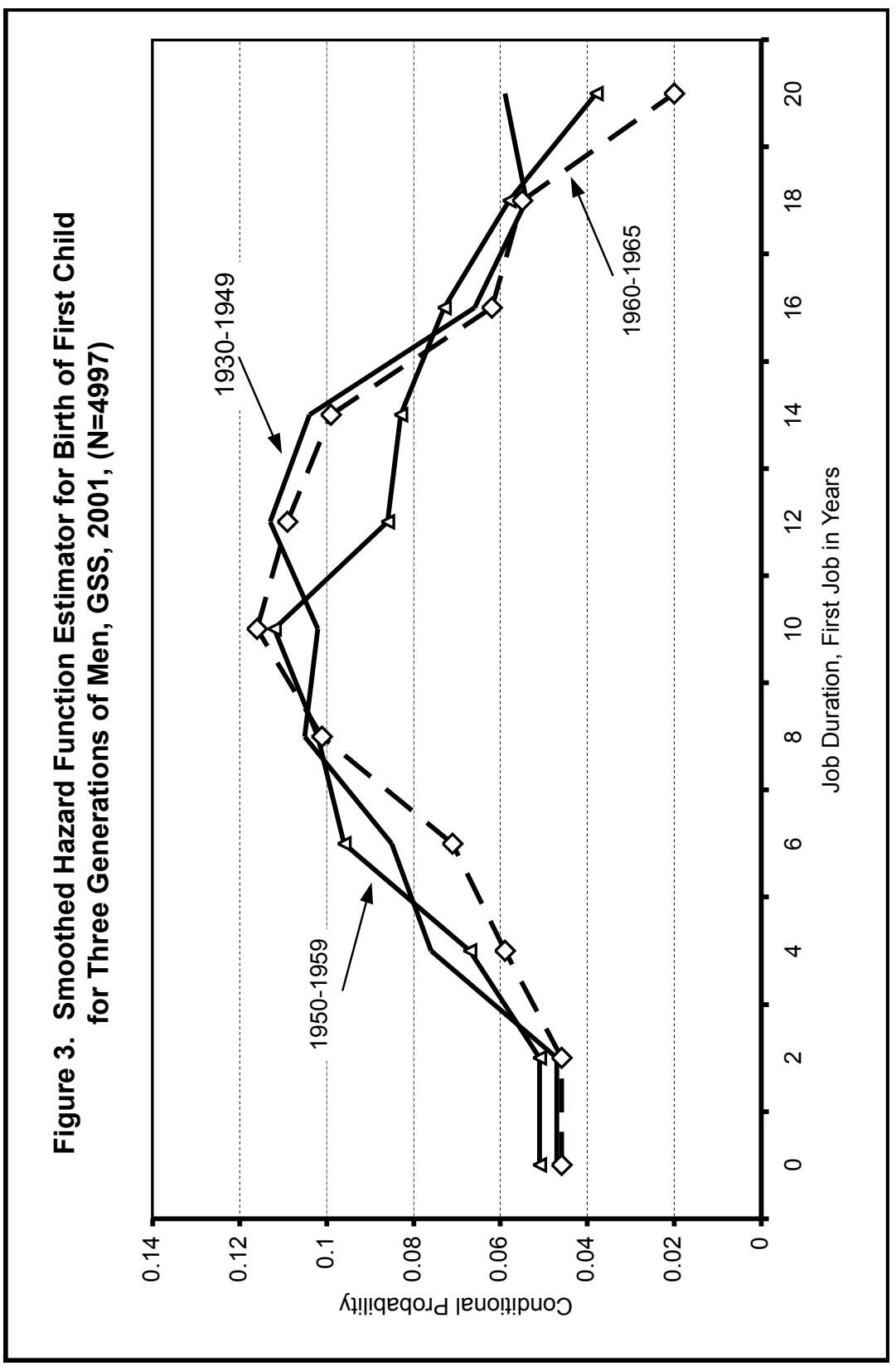

CSP 2010, 37.1-2: 77-105 
differences between the two older generations and the more recent generation evolved in two stages over the observation period. We see that for the job duration interval of less than 10 years, the chances of having a first child progressively increases in the three generations but remains lower for men born from 1960 to 1965 . For durations between 10 and 15 years, that is, after the curves have reached their maximums, the middle generation (1950-59) now clearly differs from the two generations at either extreme (1930-49 and 1960$65)$. This change seems to indicate that the effect of characteristics of the job on the risk of having a first child varies according to the duration in the job, particularly for the generations born from 1950 to 1959 and 1960 to 1965. The low propensity to have a first child for job durations of less than 10 years for men born from 1960 to 1965 may be linked to the job instability that seems to have affected most individuals newly arrived on the labour market, as we saw above (Figure 1). A large majority of men born from 1960 to 1965 in fact seem to have arrived on the labour market in the mid-1980s and early 1990s, periods that were marked by economic recessions. For job durations of more than 10 years, the behaviour of the younger generation in terms of the transition to parenthood could be attributed to two phenomena, the effects of which are not mutually exclusive: we are thinking both of the qualitative evolution of these men's working careers due to the high levels of qualification in these generations and also of the impact of the stage attained in the life cycle (for example, being in a conjugal union).

At this point in the analysis, we can observe that the characteristics of men's job do not seem to be neutral in distribution of the risk of having a first child. Although this observation may seem to be somewhat hasty, the fact remains that the coincidence of the instability of the job for men born from 1960 to 1965 with the slightly higher frequency of first birth postponement in the same generations is striking. From this point of view, our hypothesis of a differential transition to parenthood according to the characteristics of the job seems admissible. However, we will be able to further qualify these remarks through an analysis of factors associated with the risk of having a first child, since descriptive analyses only give indications that help us to develop hypotheses on the role played by characteristics of the job on the fact of having a first child. 
The Influence of Characteristics of Men's Job on the Timing of the First Birth in Canada

\section{Factors Associated with the Timing of the First Birth: Results of the Analysis}

This section attempts to more clearly define the role of characteristics of the job in association with socio-demographic characteristics. We have chosen to employ methods used in event history analysis, notably the piecewise model. In the context of this article, estimation of this model is based on the postulate that the effect of characteristics of the job on the risk of having a first child varies differently in each job duration interval. The time intervals selected for estimation of the piecewise model are: 1) less than one year in the job (less than 1 year), 2) between the first and second year (1 to 2 years), 3) between the third and fourth year ( 3 to 4 years), 4 ) between the fifth and ninth year (5 to 9 years), and finally, 5) the tenth year and over (10 years or more). For the analysis by generation, instead of five job duration intervals we will use only four, due to the low number of people associated with certain categories of the variables included in the analysis, particularly for men born from 1960 to 1965. In this case, the lower limit of the last job duration interval is set starting from the fifth year instead of the tenth year as described above.

\section{Strategies Selected for Modeling the Risk Studied}

We developed four regression models from the Stata module to estimate piecewise-constant hazard rate models. The first model evaluates the net effect, for the entire sample, of characteristics associated with the job on the risk of having a first child, in controlling for certain socio-demographic characteristics judged as relevant in the literature. The other three models correspond to each of the three birth cohorts and enable us to see whether the effect of characteristics of the job varies over the generations. This would not be seen with results estimated for the entire sample. Our results are presented in the form of odds ratios ${ }^{4}$ from the piecewise model. An odds ratio measures the average influence of the characteristic on the annual risk of experiencing the event studied, compared with a reference category. To the extent that our analysis is primarily aimed at examining the effects of characteristics of men's job on their transition to parenthood, specification of the basic risk only has a technical role of control. The results relating to this basic risk are shown at the top of Table 1 and, as presented, should not be interpreted in relation to the reference category but as directly indicating the risk of having a first child associated with each duration interval in the job.

CSP 2010, 37.1-2: 77-105 
Table 1

Role of Individual Characteristics in Men's Risk of becoming a Parent after being Hired in their Job: Odds Ratios from the Piecewise Model

\begin{tabular}{|c|c|c|c|c|}
\hline Independent Variables & $\begin{array}{c}\text { Model 1 } \\
\text { Full Sample } \\
\end{array}$ & $\begin{array}{c}\text { Model 2 } \\
1930-1949 \\
\end{array}$ & $\begin{array}{c}\text { Model 3 } \\
1950-1959 \\
\end{array}$ & $\begin{array}{c}\text { Model } 4 \\
1960-1965 \\
\end{array}$ \\
\hline Duration intervals in the first job & $(n=4997)$ & $(\mathrm{n}=2043)$ & $(n=1692)$ & $(n=1262)$ \\
\hline Less than 1 year in the first job & $0.01 * * *$ & 0.01 & 0.01 & 0.01 \\
\hline 1 to 2 years in the first job & $0.02 * * *$ & 0.01 & 0.02 & 0.01 \\
\hline 3 to 4 years in the first job & $0.03 * * *$ & $0.04^{* *}$ & 0.02 & $0.02 * *$ \\
\hline 5 to 9 years in the first job (a) & $0.06^{* * *}$ & $0.08 * * *$ & $0.08 * * *$ & $0.04 * * *$ \\
\hline 10 years or more in the first job & $0.05^{* * *}$ & na & na & na \\
\hline \multicolumn{5}{|l|}{ Generations } \\
\hline $1930-1949$ & 1.00 & $\ldots$ & $\ldots$ & $\ldots$ \\
\hline $1950-1959$ & $0.86^{* * *}$ & $\ldots$ & $\ldots$ & $\ldots$ \\
\hline $1960-1965$ & $0.88^{* * *}$ & $\cdots$ & $\cdots$ & .. \\
\hline \multicolumn{5}{|l|}{ Characteristics of the first job } \\
\hline (Part-time wage-earners) & 1.00 & 1.00 & 1.00 & 1.00 \\
\hline Full-time wage-earners, job duration less than $1 \mathrm{yr}$. & $1.42 \mathrm{~ns}$ & 1.26 & 1.16 & 2.16 \\
\hline Full-time wage-earners, job duration 1 to 2 yrs. & $2.42 * * *$ & 2.15 & 1.87 & 3.68 \\
\hline Full-time wage-earners, job duration 3 to 4 yrs. & $1.82 * *$ & 1.78 & 2.66 & 1.42 \\
\hline Full-time wage-earners, job duration 5 to 9 yrs. (a) & $1.00 \mathrm{~ns}$ & $0.70^{* *}$ & 0.91 & 1.29 \\
\hline Full-time wage-earners, job duration $10 \mathrm{yrs.} \mathrm{or} \mathrm{more}$ & $0.91 \mathrm{~ns}$ & na & na & na \\
\hline Self-employed workers, job duration less than $1 \mathrm{yr}$. & $0.85 \mathrm{~ns}$ & 0.63 & 1.52 & - \\
\hline Self-employed workers, job duration 1 to 2 yrs. & $3.26^{* * *}$ & 3.38 & 1.43 & 6.74 \\
\hline Self-employed workers, job duration 3 to 4 yrs. & $2.28 * * *$ & 1.98 & 3.92 & 1.62 \\
\hline Self-employed workers, job duration 5 to 9 yrs. (a) & 0.82 & $0.50^{* * *}$ & 0.98 & 1.03 \\
\hline Self-employed workers, job duration 10 yrs. or more & 0.78 & na & na & na \\
\hline \multicolumn{5}{|l|}{ Marital status } \\
\hline (Living in a common-law union) & 1.00 & 1.00 & 1.00 & 1.00 \\
\hline Unattached men, job duration less than $1 \mathrm{yr}$. & $3.47 * * *$ & 2.98 & 4.85 & 2.93 \\
\hline Unattached men, job duration 1 to $2 \mathrm{yrs}$. & 0.85 & 1.00 & 0.91 & 0.69 \\
\hline Unattached men, job duration 3 to 4 yrs. & 0.83 & $0.46^{* *}$ & 1.22 & 1.22 \\
\hline Unattached men, job duration 5 to 9 yrs. (a) & $0.41^{* * *}$ & $0.47^{* * *}$ & $0.58^{* *}$ & $0.22 * * *$ \\
\hline Unattached men, job duration 10 yrs. or more & $0.46^{* * *}$ & na & na & na \\
\hline Married before job 1 , job duration less than $1 \mathrm{yr}$. & $14.66^{* * *}$ & 11.62 & 23.14 & 12.13 \\
\hline Married before job 1 , job duration 1 to 2 yrs. & $3.39^{* * *}$ & $2.98^{* * *}$ & $4.48^{* * *}$ & $2.83^{* *}$ \\
\hline Married before job 1, job duration 3 to 4 yrs. & $3.80^{* * *}$ & 3.01 & 3.17 & - \\
\hline Married before job 1, job duration 5 to 9 yrs. (a) & 0.61 & 0.67 & 2.30 & - \\
\hline Married before job 1, job duration 10 yrs. or more & 0.85 & na & na & na \\
\hline Married after job 1 , job duration less than 1 yr. & $0.71 \mathrm{~ns}$ & 0.56 & 1.37 & 0.42 \\
\hline Married after job 1 , job duration 1 to 2 yrs. & $0.65^{* * *}$ & 0.78 & 0.64 & $0.52^{* *}$ \\
\hline Married after job 1, job duration 3 to 4 yrs. & 0.82 & 0.60 & 1.07 & 0.88 \\
\hline Married after job 1, job duration 5 to 9 yrs. (a) & 0.89 & 1.06 & 1.03 & $0.66^{*}$ \\
\hline Married after job 1 , job duration 10 yrs. or more & 0.99 & na & na & na \\
\hline
\end{tabular}


The Influence of Characteristics of Men's Job on the Timing of the First Birth in Canada

Table 1 (Continued)

Role of Individual Characteristics in Men's Risk of becoming a Parent after being Hired in their Job: Odds Ratios from the Piecewise Model

\begin{tabular}{|c|c|c|c|c|}
\hline Independent Variables & $\begin{array}{c}\text { Model 1 } \\
\text { Full Sample } \\
\end{array}$ & $\begin{array}{c}\text { Model 2 } \\
1930-1949 \\
\end{array}$ & $\begin{array}{c}\text { Model 3 } \\
1950-1959 \\
\end{array}$ & $\begin{array}{c}\text { Model 4 } \\
1960-1965 \\
\end{array}$ \\
\hline $\begin{array}{l}\text { Age at the beginning of the first job } \\
15-19 \text { yrs. } \\
20-24 \text { yrs. } \\
25-34 \text { yrs. }\end{array}$ & $\begin{array}{l}1.26^{* * *} \\
1.40^{* * *} \\
1.00\end{array}$ & $\begin{array}{l}1.21 \\
1.57^{* * *} \\
1.00\end{array}$ & $\begin{array}{l}1.09 \\
1.05 \\
1.00\end{array}$ & $\begin{array}{l}1.47^{* *} \\
1.56^{* * *} \\
1.00\end{array}$ \\
\hline $\begin{array}{l}\text { Highest level of education attained } \\
\text { (Secondary education or lower) } \\
\text { College } \\
\text { University }\end{array}$ & $\begin{array}{l}1.00 \\
1.00 \\
0.98\end{array}$ & $\begin{array}{l}1.00 \\
1.00 \\
0.89\end{array}$ & $\begin{array}{l}1.00 \\
1.04 \\
1.01\end{array}$ & $\begin{array}{l}1.00 \\
0.98 \\
1.13\end{array}$ \\
\hline $\begin{array}{l}\text { Place of residence } \\
\text { (Rest of Canada) } \\
\text { Québec }\end{array}$ & $\begin{array}{l}1.00 \\
1.17^{* * *}\end{array}$ & $\begin{array}{l}1.00 \\
1.27 * * *\end{array}$ & $\begin{array}{l}1.00 \\
1.08\end{array}$ & $\begin{array}{l}1.00 \\
1.13\end{array}$ \\
\hline $\begin{array}{l}\text { Parents' national origin } \\
\text { (Canadian-born parents) } \\
\text { Foreign-born parents } \\
\text { Mixed parents }\end{array}$ & $\begin{array}{l}1.00 \\
0.82^{* * *} \\
0.86^{* * *}\end{array}$ & $\begin{array}{l}1.00 \\
0.76^{*} \\
0.80^{* * *}\end{array}$ & $\begin{array}{l}1.00 \\
0.81^{*} \\
0.95\end{array}$ & $\begin{array}{l}1.00 \\
0.88 \\
0.83^{*}\end{array}$ \\
\hline $\begin{array}{l}\text { Number of siblings } \\
\text { (No siblings) } \\
1 \text { to } 2 \text { siblings } \\
3 \text { to } 4 \text { siblings } \\
5 \text { or more siblings }\end{array}$ & $\begin{array}{l}1.00 \\
1.40^{* * *} \\
1.41^{* * *} \\
1.60^{* * *}\end{array}$ & $\begin{array}{l}1.00 \\
1.35^{* * *} \\
1.31^{* *} \\
1.49^{* * *}\end{array}$ & $\begin{array}{l}1.00 \\
1.38^{* *} \\
1.44^{* *} \\
1.78^{* * *}\end{array}$ & $\begin{array}{l}1.00 \\
1.82^{* * *} \\
1.91 * * \\
1.93^{* * *}\end{array}$ \\
\hline $\begin{array}{l}\text { Religious practice at age } 15 \\
\text { (Regular practice) } \\
\text { Irregular practice } \\
\text { No practice }\end{array}$ & $\begin{array}{l}1.00 \\
0.96 \\
0.92 * *\end{array}$ & $\begin{array}{c}1.00 \\
0.91 \\
0.88^{*}\end{array}$ & $\begin{array}{l}1.00 \\
1.10 \\
0.97\end{array}$ & $\begin{array}{l}1.00 \\
0.89 \\
0.91\end{array}$ \\
\hline $\begin{array}{c}\text { Model } \chi^{2} \\
\mathrm{P}>=\chi^{2}\end{array}$ & $\begin{array}{c}28104.42 \\
0.000\end{array}$ & $\begin{array}{c}10526.11 \\
0.000\end{array}$ & $\begin{array}{c}9624.74 \\
0.000\end{array}$ & $\begin{array}{c}9257.69 \\
0.000\end{array}$ \\
\hline
\end{tabular}

Note: Reference category between parenthese; $\mathrm{na}=$ not applicable. ${ }^{* * *} \mathrm{p} \leq 0.01 ;{ }^{*} \mathrm{p} \leq 0.05 ;{ }^{*} \mathrm{p} \leq 0.10$

(a) For the analysis by generation, read job duration of 5 years or more instead of 5 to 9 years; - = few people in the latter category. 


\section{Results from the Model Estimated for the Entire Sample}

The results from model 1 (Table 1) show that characteristics of the job have an impact on the risk of becoming a parent for the first time after being hired. But this effect is only significant for job duration intervals ranging from the first to the second year and the third to the fourth year. Between the first and second year, men who have not yet had a child and are working as full-time wageearners have 2.4 times more chances of having a first child than the part-time wage-earners making up the reference group. In this same duration interval in the job and compared with the same reference group, self-employed workers are 3.3 times more likely to have a first child. However, whether for full-time wage earners or self-employed workers, this gap diminishes in subsequent job duration intervals.

For job durations of less than one year and those greater than or equal to 5 years, the characteristics associated with the job do not differently affect the risk of becoming a parent. For job duration intervals of 5 years or more, the level of the estimates obtained indicates a decrease in the likelihood of having a first child for both full-time wage earners and self-employed workers compared with part-time wage-earners. But the differences are not statistically significant. This could however signify a decline in the attractiveness of having children for some full-time wage earners and self-employed workers who may not have had a child yet. So we might also think of a deliberate choice on the part of the latter two groups to postpone the formation of a family or to simply not have any children.

Overall, 5 years duration in the job seems to represent the threshold at which characteristics associated with the job cease to be discriminant in terms of the risk of becoming a parent after being hired.

These results confirm our initial hypothesis of a differential transition to parenthood according to characteristics associated with the job. They also clearly show that the impact of characteristics associated with the job occupied at the beginning of the career varies with the job duration. We can thus imagine two groups of men based on their behaviour in terms of forming a family. The first group would be made up of men holding precarious jobs and primarily seeking job stability. Their behaviour in regard to fertility should be interpreted in terms of first birth postponement and not as a decision not to take on the responsibilities associated with having a child.

The second group is comprised of men who view their first job experiences positively, due to its characteristics, and have well structured plans for a family. Essentially, this group is made up of full-time wage earners and self-employed workers. We think that these two types of employment encourage formation of a family, at least for the men in our analysis sample. This is because of the better prospects they foresee in terms of both stability and fulfillment in their work career, and perhaps also in terms of income. This result corroborates the theoretical hypotheses regarding the effect of uncertainty and 
The Influence of Characteristics of Men's Job on the Timing of the First Birth in Canada

job precariousness on the postponement of family events (Blossfeld and Mills 2003; McDonald 2001). Similarly, to a certain degree, the thesis advanced by Oppenheimer (1994) based on the deterioration of young men's economic situation is admissible in that the results observed seem to indicate that for men with a precarious economic status, it is in fact a question of a delay in the transition to parenthood and not of a decision not to have at least one child.

Other individual characteristics included in the model that have a significant impact are: marital status, generation, rate activity of the women over the period 1945 to 2001, age at the beginning of the job, place of residence, parents' national origin, number of siblings, and religious practice at age 15 . In regard to marital status, we wanted to see whether its role changes with the time spent in the job. The overall results show that marital status plays a significant role in the conditional probability of having a first child. Thus, for the job duration interval of less than 1 year, unattached men are roughly 3 times more likely to have a first child than those in common-law unions (the reference group). But this relation changes direction between the first and fourth year after entry into the job occupied at the beginning career, while this same relation is only significant for durations equal to or more than 5 years, indicating that unattached men $^{5}$ are less likely to become parents than men in common-law unions. This latter result could be due to the fact that over time, as the commonlaw union becomes more stable, the partners often decide to strengthen their relationship by giving birth to at least one child. This behaviour would be supported by the fact of being able to count on two incomes for individuals in a situation of precariousness. We think that for men in common-law unions, the first few years in the job may also correspond to a period of stabilization of the union, a time less favorable to carrying out plans to have a child.

On the other hand, when men are married before their job, the chances of having a first child increase in the first four years after their hiring. In fact, for the job duration interval of less than one year, men married before the job of at least six months who have not yet had a child are 15 times more likely to become a parent than those in common-law unions. This gap diminishes considerably between the first and fourth years. Firstly, we think that for men married before entry into a job of at least six months, obtaining the job accelerates the transition to fatherhood, all other things being equal. Secondly, the differences in the first few years of the job between men in a common-law union and those who were married before they were hired are a reflection of a delay in the transition to parenthood for men in common-law unions rather than a lesser likelihood of having at least one child. This might be explained by the fact that spouses in common-law unions may keep an eye on the evolution of their relationship as a couple a little longer than married people, due to the slightly greater fragility that characterizes common-law unions.

Moreover, the fact of a man being married after entry into the job only has a significant impact in the job duration interval ranging from the first to the

CSP 2010, 37.1-2: 77-105 
second year. The risk associated with this factor indicates that, between the first and second year in the first job, men married after being hired are less likely to have a first child than those in common-law unions. We think that men who marry after they are hired in their job wait for a period of time before starting to form a family, a period that corresponds to their becoming established in stable work and accumulating the resources needed to cover the expenses of both the marriage and setting up as a couple: hence the delay in the transition to parenthood. But because the duration since the couple became established in a marriage or common-law union is not taken into account, we cannot be sure of how accurate this tentative explanation may be. The variation in the effect of marital status according to the duration in the job prompts the following commentary: if we had examined the role of marital status during the entire observation period, as is often done, we would probably have found less clear a relationship that would undoubtedly mask the variation in the impact and, to a certain degree, the change in the direction of causality according to the job duration interval. On a methodological level, these results thus underscore the pertinence of the piecewise model in estimating the effect of marital status. And, sociologically speaking, they show the state of mind associated with the different modalities of life as a couple, while emphasizing the importance of young people's economic situation at the time they begin adult life.

In regard to birth cohorts, we see a significant effect of marital status on the risk of having a first child, indicating that men in the younger generations are more likely to have their first child after being in their job in the first work episode when compared with men born in 1930-1949. The effect of this variable has changed direction when women's labour force participation rates were introduced in the model. This result seems to be surprising, since we took for granted that younger generations are living in the post-transitional context characterized by low fertility, changing mentalities about family formation and also by more precarious conditions for young people starting their career. But this result goes in the same direction as what was observed for women of the same generations. (Bingoly-Liworo and Lapierre-Adamcyk 2006).

With regard to the women's labour force participation (measured by women's activity rate from 1945 to 2001), introducing it in the model does not modify the effect of other independent variables, particularly for those variables associated with employment. However it has a significant, but negative impact on the men's risk to have their first child after their entry in their job. Hence, the likelihood for men to have their first child after being in their job is reduced when women's activity rates increase. This result is often observed when women's behaviour is being analyzed.

Age at the time of hiring has a significant effect, showing that men who entered the labour market before age 25 are more likely to become parents than those aged 25 to 34 . We did not expect this result, since, based on the notion of "catching up" (that is, that people who were older at the time of hiring would be

CSP 2010, 37.1-2: 77-105 
The Influence of Characteristics of Men's Job on the Timing of the First Birth in Canada

more attracted by the idea of family life), we surmised that entering the labour market at an older age would encourage these men to start a family sooner. In reality, we had not considered the fact that men who entered the labour market in their thirties would undoubtedly have particular characteristics such as having pursued their studies for longer periods, putting priority on succeeding in their work career, or being governed to a greater degree by the values of modernity. The results obtained for this factor, based on an analysis by generation, seem to support this explanation, in the sense that this same impact is found to be significant for men born from 1960 to 1965 .

Province of residence plays a significant role regarding men's risk of having a first child after being hired in their job. Men living in Québec have a $17 \%$ higher risk of having a first child than men living in the rest of Canada. This result might be explained by the heterogeneity of the sample, in terms of the generations of men considered from the viewpoint of the rate of fertility decline in Canada. Elsewhere in Canada, this fertility decline seems to have begun a little earlier, whereas in Québec the pioneers of this change appear to belong to slightly younger generations than those launching this same trend in the rest of Canada. This reasoning is supported by the evolution of the effect of this same factor over the three generations; the effect is only discriminant in the oldest generation.

The number of siblings increases the likelihood of becoming a parent. The greater is the number of siblings, the more likely men are to have a first child. This result has often been observed for women, and seems to be explained by the fact that individuals from large families apparently try to reproduce the socialization environment they had known in their childhood, especially in terms of the frequency of the first birth. On the other hand, the parents' national origin has a negative effect, showing that men with two parents born outside Canada and those with one Canadian-born and one foreign-born parent (mixed-parent couples) are less likely to have a first child than those with two Canadian-born parents. This result is contrary to what we had expected. In fact, in the specific case of the first birth, entry into a stable work situation is far more determinant than ethnic origin. This could signify economic precariousness for men whose parents were born outside Canada. On this topic, a number of studies often mention immigrants' problems in work integration (Piché et al. 1997). The differences shown here could be explained by the extent and quality of the social network enjoyed by men with Canadian-born parents. Making use of the network developed and maintained by their parents, "old stock" Canadian youth arrive on the labour market with a slight advantage that translates into access to more stable jobs. On the other hand, in most cases, in the early years of their working career, immigrants' children have to cope with jobs that are less reassuring in terms of stability and income. Religious practice has little effect, except for a low risk for non-practicing individuals. And there is no significant

CSP 2010, 37.1-2: 77-105 
difference in the likelihood of becoming a parent according to the level of education attained.

\section{Role of Individual Characteristics in each of the Three Generations}

Models 2 to 4 in Table 1 show the results of effects estimated for characteristics included in analyses of each of the three generations. Regardless of the generation considered, the characteristics of the job only play a significant role in the risk of having a first child for full-time wage earners and self-employed workers born from 1930 to 1949. Men of this generation see their chances of becoming a parent decline significantly as of the fifth year in the first job. For job duration intervals of less than 5 years, although the differences are not significant, in each of the three generations the level of the odds ratios seems to indicate a greater propensity to have a first child for full-time wage-earners and self-employed workers compared with part-time wage-earners. Overall, these results surprise us, in that they are contrary to what we were expecting. Our hypothesis was that characteristics associated with the job occupied at the beginning career should have a growing differential impact from the oldest to the youngest generation, and this is not the case. The disappearance of differences across the three generations according to characteristics of the job could be explained by the fact that, for men, realization of their plans to have a child is a process largely dependent on union formation. Union formation itself can be said to lie within a perspective of personal emancipation that is strongly dependent on one's work status. We therefore think that within a single generation, the impact of characteristics associated with the job is related to one's marital status, and that it is marriage in particular that makes the difference. This could mean that, for men in these generations, the fact of being married would be associated with sufficient stability of resources to cover their financial responsibilities for dependents.

The results obtained for the three generations highlight two groups of socio-demographic factors. On the one hand are characteristics for which the impact has remained the same over the generations: marital status (the fact of being unattached or married before the hiring), and number of siblings. These two factors have a positive effect on the risk of having a first child, regardless of the generation. On the other hand are characteristics for which the effect has changed or become stronger over time: age at the beginning of the job and parents' national origin. The effect of these two factors varies over the three generations. For age at the beginning of the first job, this could be explained by the dissemination of new family behaviours associated with the second demographic transition (van de Kaa 1987), particularly for men born from 1950 to 1959 . We think that men who reached adulthood during this time of upheaval were affected by these changes. As such values were still being disseminated;

CSP 2010, 37.1-2: 77-105 
The Influence of Characteristics of Men's Job on the Timing of the First Birth in Canada

they appeared to have played a role in, among other things, neutralizing the differences by age. In virtually all societies, individuals aged 15 to 34 are in fact largely concerned with testing out new values. For the generation born from 1960 to 1965 , the significant differences by age at the beginning of the job might be linked to the impact of prolonging the period of studies and other associated effects. In this regard, we think that the men who did not enter the labour market until their thirties had remained at their studies for a slightly longer period of time. And we know that most people who leave the education system at a later age (well-educated individuals) are less likely to have a first child, due to many factors: the time needed to become established professionally and as a couple, and also given their attachment to post-materialist values. Finally, in the oldest generation, the parents' national origin was significantly related to the risk of having a first child. This relation indicates that men with foreign-born parents and those for whom one parent is Canadian-born are less likely to have a first child than men with two Canadian-born parents, whereas for the generations born from 1950 to 1959 and 1960 to 1965 , the differences by the parents' national origin are relatively less important.

\section{Conclusion and Discussion}

The objective of this study was to illustrate the impact of characteristics associated with the job occupied at the beginning career on men's transition to parenthood after their hiring. The hypothesis tested is that characteristics associated with the job lead to a differential transition to parenthood, characterized by a greater likelihood of having a first child for men whose job has some stability, compared with those whose job is unstable and precarious.

First, the results of descriptive analyses relating to the timing of the transition to parenthood demonstrate the importance of first birth postponement for male generations born from 1960 to 1965 compared with men born from 1930 to 1949 and 1950 to 1959 , as well as the progressive increase in the likelihood of having a first child prior to the tenth year spent in the labor market. Next, the results of the multivariate analyses clearly show that full-time wageearners and self-employed workers are more strongly inclined to have a first child than part-time wage-earners, thus validating our initial hypothesis. These results also confirm the findings from the descriptive analysis to the effect that the impact of characteristics associated with the job occupied at the beginning career varies according to the time duration in the job.

Four main lessons can be drawn from our findings. Firstly, the process leading to parenthood from the time of entry into the job at the beginning career requires, independently of the characteristics of this job, a period that seems to correspond to a phase of stabilization in the job, when all other life plans are more or less put on hold. Secondly, our results show two different transition-to-

CSP 2010, 37.1-2: 77-105 
parenthood scenarios. The first appears to correspond to a faster transition, associated with the quality of the job. In other words, when the job at the beginning career is stable and offers better prospects, it favours the birth of a first child more quickly after labour market entry. On the other hand, the second scenario appears to correspond to a slower transition that essentially depends on the stage attained in the life cycle. This transition is seen when job status is precarious and less well defined. This validates the hypotheses about uncertainty and economic precariousness (McDonald 2001; Blossfeld and Mills 2003; Oppenheimer 1994; Palomba 2001) that indicate that, in conditions of job precariousness, young people tend to postpone the birth of a first child.

Thirdly, men's behaviour in regard to the transition to parenthood cannot simply be explained by economic considerations. Traditional socio-demographic and cultural factors continue to play a part, but for most of them, the differences appear to become less and less significant over time. However, the very significant impact of the status of being married before the job seems to indicate that this factor is the only theoretical marker strongly associated with the birth of the first child. Its essentially discriminant effect in the first few years after hiring leads us to believe that the job accelerates the carrying out of men's plans to have a child for those who marry before obtaining a job lasting six months or more. Fourthly, when family formation is seen according to the traditional model of succession, in predetermined order, of the different stages in the transition-toadulthood process, the timing of the first birth should not correspond to the time of hiring in the job. This could mean that we should also look for a partial explanation of the phenomenon of first birth postponement in the temporal extension of the stages leading to adult autonomy. The already strong trend toward first birth postponement could consequently intensify if no action is considered to try to improve the situation of young people starting out in their working lives. We think that family support to help young couples become established is increasingly needed, and that governments should adopt measures to support the transition from people's studies to the labour market, in taking a long-term perspective, as the future is both an individual and a collective responsibility.

To heighten the significance of these results, it would be desirable to use data that enable one to jointly consider the characteristics of both spouses. Becoming a parent today is increasingly a deliberate choice made by the couple, less influenced by the immediate social environment and much more dependent on both the spouses' life goals and the way the latter simultaneously experience the events associated with personal emancipation.

\section{Acknowledgement}

Responsibility for any errors rests with the author. 
The Influence of Characteristics of Men's Job on the Timing of the First Birth in Canada

\section{End Notes}

1. In the GSS 2001, employment is observed through work episodes. An individual (or respondent) may have occupied many jobs, given that only work interruptions lasting three months or more are considered as ending a job episode. In other words, those who lost their job and found another one within a period of less than three months are not considered as having a new episode. This makes it difficult to talk about the 'first job'. In this text, we call a job, the job (or jobs) occupied during the first work episode. We will also use the following terms : 'first experiences in the labour market' or 'job occupied at the career beginning' to refer to labour market participation during the first employment episode.

2. The literature generally identifies five main events in the process of transition to adulthood: completion of studies, labour market entry, departure from the parental home, formation of a first union and the birth of a first child..

3. The results of these tests are significant to less than $1 \%$. These two tests verify, according to the sample stratification variables, homogeneity between subpopulations at the beginning and end of the observation period respectively.

4. The odds ratio should be interpreted in relation to the reference category, which is attributed the value 1 . A category of the independent variable with an associated odds ratio of greater than 1 means that this category increases men's risk of becoming a parent after being hired in the job occupied at the beginning career compared with the reference category. Conversely, an odds ratio of less than 1 indicates that the category involved decreases this risk. The effect of independent variables whose value, for a respondent, may vary over the observation period should be interpreted in the same way as the effect of an independent variable whose value would not change.

5. The category "unattached men" essentially refers to men who changed their marital status during pregnancy (the case of union dissolutions) and possibly to those in situations not falling under the definition of a common-law union, who apparently stated they had never been part of a couple. 


\section{References}

Bingoly-Liworo, G. and E. Lapierre-Adamcyk. 2006. "Devenir parent au Canada. L'effet de l'allongement des études." Cahiers Québécois de Démographie 35(2): 102-140.

Blossfeld, H.-P. and M. Mills. 2003. "Globalization, uncertainty and changes in early life courses." Zeitschrift für Erziehungswissenschaft 6: 188-218.

Bowlby, G. 2000. "La transition des études au marché du travail." L'emploi et le revenu en perspective 12(1): 3-35.

Cox, D. R. 1972. "Regression models and life tables." Journal of the Royal Statistical Society, series BJ 34: 187-220.

De Wit, M. L. and F. Rajulton. 1992. "Education and timing of parenthood among Canadian women: a cohort analysis." Social Biology 39(1-2): 109-122.

Duval, L. 1997. Aspects économiques de la vie des jeunes familles biparentale. État de la question. Madeleine Gauthier (ed.), Sainte-Foy: INRSCulture et Société.

Easterlin, R. A. 1973. "Relative economic status and the American fertility swing," in E. B. Sheldon (ed.), Family economic behaviour: problems and prospects. Philadelphia: Lippincott. Pp. 166-223.

Easterlin, R. A. 1976. "The conflict between aspirations and resources." Population and Development Review 2(3): 417-426.

Easterlin, R. A. C. Macdonald and D. J. Macunovich, 1990. "How have American baby boomers fared? Earnings and economic well-being of young adults, 1964-1987." Journal of Population Economics 3(4): 277-290.

Easterlin, R. A. and E. Crimmins. 1991. "Private materialism, personal selffulfilment, family life and public interest: the nature, effects and causes of recent changes in the values of American youth." Public Opinion Quarterly 55: 499-533.

CSP 2010, 37.1-2: 77-105 
The Influence of Characteristics of Men's Job on the Timing of the First Birth in Canada

Galland, O. 1985. "Formes et transformations de l'entrée dans la vie adulte." Sociologie du travail 27(1): 32-52.

Galland, O. 1996. "L'entrée dans la vie adulte en France. Bilan et perspectives sociologiques." Sociologie et sociétés 28(1): 37-46.

Gauthier, M. 1991. L'insertion de la jeunesse Canadienne en emploi. Research report submitted to Statistics Canada. Québec: Institut québécois de recherche sur la culture.

Gauthier, M. and J. Charbonneau et al. 2002. Jeunes et fécondité : les facteurs en cause. Revue de la littérature et synthèse critique. Institut national de la recherche scientifique-Urbanisation, Culture et Société.

Henripin, J. 1989. Naître ou ne pas être, Québec. Institut québécois de recherche sur la culture.

Lapierre-Adamcyk, E. and N. Marcil-Gratton. 1987. "Les vrais problèmes de la décroissance de notre population.” La Presse.

Le Goff, J.-M. 2003. Modélisation des événements du parcours de vie. Une introduction. Centre lémanique d'analyse des parcours et mode de vie et laboratoire de démographie et d'études familiales. Université de Lausanne et de Genève. Available at http:// www2.unil.ch/pavie/documentation/introduction.htm

Leridon, H., Y. Charbit, P. Collomb, J. P. Sardon and L. Toulemon. 1987. La seconde révolution contraceptive: la régulation des naissances en France de 1950 à 1985. INED/Puf. Coll. Travaux et documents, Cahier 117.

McDonald, P. 2001. "Theory pertaining to low fertility." Paper presented at the IUSSP Conference on Perspectives on Low Fertility: Trends, Theories and Policies. Tokyo, Japan, 21-23 March 2001.

Mongeau, J., G. Neill and C. Le Bourdais. 2001. "Effet de la précarité économique sur la formation d'une première union au Canada." Cahiers Québécois de Démographie 30 (1): 2-29.

Morissette, R. 2002. "Les gains cumulatifs chez les jeunes travailleurs." L'emploi et le revenu en perspective 14 (4): 5-13.

Morissette, R. and A. Johnson. 2005. Les bons emplois disparaissent-ils au Canada? Catalogue No. 11F0019 (239). Ottawa: Statistics Canada.

CSP 2010, 37.1-2: 77-105 
Oppenheimer, V. K. 1994. "Women's rising employment and the future of the family in industrial societies." Population and Development Review 20 (2): 293-342.

Palomba, R. 2001. "Postponement of family formation in Italy within the Southern European context." Paper presented at the IUSSP Conference on Perspectives on Low Fertility: Trends, Theories and Policies. Tokyo, Japan, 21-23 March 2001.

Piché, V., J. Renaud and L. Gingras. 1997. "Immigration et insertion économique à Montréal: le rôle de l'origine nationale," in J. L. Rallu, Y. Courbages and V. Piché (eds.), Anciennes et nouvelles minorités : démographie, culture et politique. Coll. Congresses and Colloquia. Paris, France: J. Libbey-INED, 17. Pp. 89-111.

Ravanera, Z. R., F. Rajulton, T. K. Burch and C. Lebourdais. 2002. "The early life courses of Canadian men: analysis of timing and sequences of events." Canadian Studies in Population 29 (2): 293-312.

Roussel, L. 1987. "Deux décennies de mutations démographiques (1965-1985) dans les pays industrialisés." Population 42(3): 429-448.

Tichit, C. and É. Lelièvre. 2006. "Analyse du passage à l'âge adulte à l'épreuve de l'approche biographique : seuil, transition ou observation incertaine?," in Philippe Antoine and Éva Lelièvre (eds.), États flous et trajectoires complexes. INED. Pp. 197-218.

van de Kaa, D. J. 1987. "Europe's second demographic transition.” Population Bulletin 42(1). Washington, DC: Population Reference Bureau.

Vosko, L. F., N. Zukewich and C. Cranford. 2003. "Le travailleur précaire: une nouvelle typologie de l'emploi." L'emploi et le revenu en perspective 4(10): 17-28.

Westoff, C. F. and N. B. Ryder. 1977. The contraceptive revolution. Princeton, NJ: Princeton University Press. 
The Influence of Characteristics of Men's Job on the Timing of the First Birth in Canada

Appendix

Number of Respondents Excluded from the Analysis by Reason and Cases of Right Censoring

\begin{tabular}{l|c}
\hline \multicolumn{1}{c|}{$\begin{array}{c}\text { Sample Submitted for Probability Analysis of Transition to Parenthood } \\
\text { after Hiring in the First Job }\end{array}$} & Men \\
\hline \hline & \\
$\begin{array}{l}\text { Respondents aged } 36 \text { to } 71 \text { inclusively who stated they had worked regularly for } \\
\text { at least six months in the first job }\end{array}$ & 6,764 \\
\hline & \\
Reasons for exclusion & \\
- Under 15 years of age at birth of the first child & 11 \\
- First child born before entry into the first job & 207 \\
- Immigrants having had their first child before coming to Canada & 72 \\
- No responses for certain variables included in the analysis & 88 \\
Total excluded & 378 \\
- Number of valid cases for generations born 1930-1971 & 6,386 \\
\hline
\end{tabular}

Source: GSS, 2001

CSP 2010, 37.1-2: 77-105 